\title{
Água aquecida e radiação UV-C no controle pós-colheita de Cryptosporiopsis perennans em maçãs
}

\author{
Vinícius Adão Bartnicki(1), Rosa Maria Valdebenito-Sanhueza( ${ }^{(2)}$, Cassandro Vidal Talamini do Amarante(1), \\ Luis Antônio Suita de Castro( ${ }^{(3)}$, Mara Regina Rizzatti(i) e João Antônio Vargas de Souza(4)
}

\begin{abstract}
(1)Universidade do Estado de Santa Catarina, Centro de Ciências Agroveterinárias, Departamento de Agronomia, Avenida Luiz de Camões, № 2.090, Bairro Conta Dinheiro, CEP 88520-000 Lages, SC. E-mail: vinibart@hotmail.com, amarante@cav.udesc.br (2)Proterra Engenharia Agronômica, BR 116, o 7.320, Bairro Fátima, CEP 95200-000 Vacaria, RS. E-mail: rosamaria@m2net.com.br ${ }^{(3)}$ Embrapa Clima Temperado, Rodovia BR 392, Km 78, Caixa Postal 403, CEP 96001-970 Pelotas, RS. E-mail: suita@cpact.embrapa.br (4)Pontifícia Universidade Católica do Rio Grande do Sul, Centro em Pesquisa e Desenvolvimento em Física, Grupo de Física das Radiações, Avenida Ipiranga, no 6.681-96A, CEP 90619-900 Porto Alegre, RS. E-mail: marar@pucrs.br
\end{abstract}

Resumo - O objetivo deste trabalho foi avaliar a colonização de Cryptosporiopsis perennans na epiderme de maçãs e a eficiência da aplicação de água aquecida e radiação UV-C no controle desse patógeno. Em maçãs submetidas à inoculação de $C$. perennans, a colonização de lenticelas e das áreas adjacentes pelo patógeno foi avaliada por microscopia eletrônica de varredura. A sensibilidade dos conídios de C. perennans aos tratamentos foi avaliada em suspensão aquosa, às temperaturas de $28,45,50$ e $55^{\circ} \mathrm{C}$, por 15 e $30 \mathrm{~s}$, e às doses de radiação UV-C de $0,018,0,037,0,075,0,150,0,375,0,750,1,500$ e 3,000 kJ m². Em maçãs submetidas à inoculação de C. perennans, foram avaliados os efeitos de $0,375,0,750$ e $1,500 \mathrm{~kJ} \mathrm{~m}^{-2}$ de radiação UV-C e da aspersão de água aquecida à $50^{\circ} \mathrm{C}$, por 15 e $30 \mathrm{~s}$ no controle do patógeno. $\mathrm{O}$ fungo produziu abundante micélio e conídios nas lenticelas e nas áreas adjacentes, na epiderme das maçãs. A água aquecida a $50^{\circ} \mathrm{C}$ por $15 \mathrm{~s}$ e à dose de radiação de UV-C de $0,750 \mathrm{~kJ} \mathrm{~m}^{-2}$ reduzem em mais de $99 \%$ a sobrevivência de conídios. A aspersão de água aquecida a $50^{\circ} \mathrm{C}$ por $15 \mathrm{~s}$ e à dose de radiação de UV-C de $0,375 \mathrm{~kJ} \mathrm{~m}^{-2}$, controlam C. perennans em maçãs.

Termos para indexação: Malus domestica, desinfestação, podridão-olho-de-boi, pós-colheita, radiação UV-C, tratamento térmico.

\section{Heated water and UV-C radiation to postharvest control of Cryptosporiopsis perennans on apples}

\begin{abstract}
The objective of this work was to assess the colonization of Cryptosporiopsis perennans in the epidermis of apples and the efficiency of heated water and UV-C radiation application to control this pathogen. In apples inoculated with $C$. perennans, the colonization of lenticels and adjacent areas by the pathogen was observed by electronic scanning microscopy. The sensitivity of $C$. perennans conidia was evaluated in aqueous suspension, at temperatures of $28,45,50$ and $55^{\circ} \mathrm{C}$ for 15 and $30 \mathrm{~s}$, and at UV-C radiation doses of 0.018 , $0.037,0.075,0.150,0.375,0.750,1.500$ and $3.000 \mathrm{~kJ} \mathrm{~m}^{-2}$. The effects of UV-C radiation doses at $0.375,0.750$ and $1.500 \mathrm{~kJ} \mathrm{~m}^{-2}$ and heated water at $50^{\circ} \mathrm{C}$, sprayed during 15 and $30 \mathrm{~s}$ were evaluated for controlling C. perennans in apples inoculated with the pathogen. The fungus produced abundant mycelium and conidia in lenticels and adjacent areas on the epidermis of the apples. The heated water at $50^{\circ} \mathrm{C}$ during $15 \mathrm{~s}$ and a $0.750 \mathrm{~kJ} \mathrm{~m}^{-2} \mathrm{UV}-\mathrm{C}$ radiation dose reduced conidia survival in more than $99 \%$. Heated water sprayed at $50^{\circ} \mathrm{C}$ during $15 \mathrm{~s}$ and a UV-C radiation dose of $0.375 \mathrm{~kJ} \mathrm{~m}^{-2}$ control $C$. perennans in apples.
\end{abstract}

Index terms: Malus domestica, desinfestation, bull's eye rot, postharvest, UV-C radiation, heat treatment.

\section{Introdução}

As doenças pós-colheita que causam as maiores perdas de maçãs no Brasil são o mofo-azul (Penicillium expansum Link ex Fries) e a podridãoolho-de-boi [Cryptosporiopsis perennans (Zeller \& Childs) Wollenweber (1939)] (Valdebenito-Sanhueza, 2002). Os métodos de controle dessas doenças incluem medidas que assegurem a menor suscetibilidade dos frutos à infecção e uma menor pressão de inóculo.

Nos tratamentos para controle de conídios associados à água da lavagem das maçãs, são recomendados produtos com diferentes formulações de cloro orgânico e inorgânico. No entanto, os tratamentos com cloro livre, apesar de serem altamente eficazes, causam corrosão do maquinário processador e poluição do

Pesq. agropec. bras., Brasília, v.45, n.2, p.124-131, fev. 2010 
meio ambiente. Processos alternativos para esse fim, que não utilizam cloro livre, podem ser empregados, tais como o tratamento térmico e a radiação ultravioleta (UV-C) (Gordon et al., 1993).

Conídios de patógenos têm mostrado inibição da germinação quando submetidos a temperaturas altas na faixa de 40 a $70^{\circ} \mathrm{C}$. Estudos in vitro têm mostrado que conídios de muitos fungos são inativados quando expostos à temperatura de $60^{\circ} \mathrm{C}$ por 5 a $10 \mathrm{~min}$ (Civello et al., 1997). O método hidrotérmico atinge conídios e infecções quiescentes, presentes na superfície ou nas primeiras camadas celulares do fruto. Muitos frutos toleram temperaturas de 50 a $60^{\circ} \mathrm{C}$ por até $10 \mathrm{~min}$, e exposições por tempos menores a essas temperaturas podem controlar patógenos de pós-colheita sem causar danos ao fruto (Lurie et al., 1998). No Brasil, em estudos com maçãs 'Fuji', a aspersão de água aquecida a $53^{\circ} \mathrm{C}$ durante $30 \mathrm{~s}$ controlou Botryosphaeria dothidea (Oster, 2004).

O modo de ação da radiação UV-C pode ser pela redução dos propágulos na superfície dos frutos, por meio do efeito germicida, ou pela indução de resistência no hospedeiro (Stevens et al., 2005). Aradiação ultravioleta com comprimento de onda próximo de $254 \mathrm{~nm}$ (UV-C) destrói as estruturas do patógeno, inibe a germinação ou retarda o desenvolvimento do fungo por meio de desnaturação proteica e desorganização da membrana plasmática (Wolfe, 1990). Moy (1983) verificou que a radiação UV-C na dose de $1,10 \mathrm{~kJ} \mathrm{~m}^{-2}$ é suficiente para reduzir a viabilidade de conídios de Rhizopus stolonifer in vitro. Camili et al. (2004) mostraram que a radiação UV-C na dose de $0,84 \mathrm{~kJ} \mathrm{~m}^{-2}$ apresentou efeito germicida sobre conídios de Botrytis cinerea, e doses entre 0,2 e $0,6 \mathrm{~kJ} \mathrm{~m}^{-2}$ retardaram e diminuíram sua germinação. In vivo, a dose de $5,4 \mathrm{~kJ} \mathrm{~m}^{-2}$ foi eficiente contra a população epífita de $P$. expansum em maçãs 'Fuji' (Valdebenito-Sanhueza \& Maia, 2001).

Não existem informações documentadas acerca da colonização de $C$. perennans em maçãs. O conhecimento das relações patógeno-hospedeiro é necessário para definir estratégias de controle do patógeno, e pode ser obtido pela técnica de microscopia eletrônica de varredura. Adicionalmente, relatos sobre a sensibilidade in vitro e in vivo de conídios C. perennans à água aquecida e à radiação UV-C não foram encontrados na literatura.

O objetivo deste trabalho foi avaliar a colonização de $C$. perennans na epiderme de maçãs e a eficiência da aplicação de água aquecida e radiação UV-C no controle desse patógeno.

\section{Material e Métodos}

Os experimentos foram realizados em 2008, na Embrapa Uva e Vinho, Estação Experimental de Fruticultura Temperada (Vacaria, RS), e na Embrapa Clima Temperado (Pelotas, RS). Em todos os ensaios, foi utilizado o isolado $\mathrm{Cp} 5$ de $C$. perennans, obtido a partir de maçãs 'Fuji' com sintomas típicos de podridãoolho-de-boi, provenientes de um pomar da região de Vacaria, RS, pertencente à coleção da Embrapa Uva e Vinho. O cultivo e a manutenção do isolado foram feitos em BDA.

As suspensões de conídios foram preparadas a partir de colônias com 15 dias da repicagem, desenvolvidas em placas contendo BDA e incubadas a $22^{\circ} \mathrm{C}$ sob exposição à luz fluorescente contínua (luz do dia). As colônias foram cobertas com $10 \mathrm{~mL}$ de água destilada esterilizada contendo Tween $80(0,001 \%)$. A concentração de conídios desejada foi ajustada com auxílio do hemacitômetro.

Para a análise da colonização da epiderme do fruto por C. perennans, foram utilizadas maçãs 'Maxi Gala' (calibre 198) e 'Fuji Kiku' (calibre 198), cultivares precoce e tardia, respectivamente. A primeira tinha quatro meses e a segunda sete meses de armazenamento em atmosfera controlada (AC). Os frutos, sem ferimentos prévios, foram selecionados e submetidos à inoculação artificial de discos de micélio de C. perennans ou discos de papel filtro de $5 \mathrm{~mm}$ de diâmetro embebidos na suspensão de conídios do patógeno $\left(1 \mathrm{x} 10^{6}\right.$ conídios $\left.\mathrm{mL}^{-1}\right)$. As inoculações foram feitas em dois locais opostos da região equatorial das maçãs. Após a deposição dos discos, as áreas submetidas à inoculação foram cobertas com algodão umedecido fixado com fita adesiva, segundo o método descrito por Guerra (2007).

Para 'Maxi Gala', a incubação foi realizada em luz fluorescente contínua (luz do dia) a $22^{\circ} \mathrm{C}$, durante 48 horas e sete dias. As maçãs 'Fuji Kiku' foram submetidas à inoculação de discos de micélio do patógeno e foram incubadas por 13 dias a $22^{\circ} \mathrm{C}$, sob luz fluorescente contínua (luz do dia). Em três frutos homogêneos de cada método de inoculação, foram 
coletadas amostras de tecido contendo lenticelas e áreas adjacentes (2x2 mm da região inoculada).

Para a análise da colonização da epiderme por meio de microscopia eletrônica de varredura, as amostras foram preparadas segundo o método descrito por Castro (2002). A formulação do fixador (Karmovisk) foi ajustada às condições ideais de concentração, $\mathrm{pH}$ e molaridade. $\mathrm{O}$ fixador foi aplicado à temperatura ambiente, por imersão, com tempo de ação de duas horas. A pós-fixação foi feita com tetróxido de ósmio $\left(\mathrm{OsO}_{4}\right)$ tamponado a $1 \%$, durante uma hora, para garantir a estabilização da forma. Após a fixação, o material foi desidratado em banhos duplos de etanol a 30, 50, 70, 80, 95 e 100\%. Posteriormente, o álcool foi substituído por gás carbônico liquefeito, no aparelho de ponto crítico. Todas as amostras foram colocadas no suporte porta-amostras do microscópio ("stub"), de acordo com a melhor orientação em relação ao feixe de varredura e ao coletor de elétrons secundários. As amostras foram identificadas e metalizadas com ouro, depositado pelo processo de "sputtering" para que os átomos atingissem toda a superfície do material. Para a obtenção de informações da topografia da superfície, foram utilizados elétrons secundários (baixa energia) para captação das imagens, provenientes da interação do feixe primário com a camada de ouro que recobre o espécime. O material foi avaliado em um microscópio de varredura modelo DSM 940A (Carl Zeiss, Oberkochen, Alemanha). Foram usadas tensões aceleradoras de $10 \mathrm{kV}$. As amostras foram visualizadas com ampliações de 200 e 1.000 vezes para 'Fuji Kiku' e 'Maxi Gala', respectivamente.

Para avaliação in vitro da sensibilidade de conídios de $C$. perennans à água aquecida, $0,1 \mathrm{~mL}$ da suspensão de $1 \times 10^{4}$ conídios $\mathrm{mL}^{-1}$ foi transferido a tubos contendo $3 \mathrm{~mL}$ de água às temperaturas desejadas, em banho-maria. Os tratamentos utilizados foram: $28^{\circ} \mathrm{C}$ por $15 \mathrm{~s}$ (testemunha); $45^{\circ} \mathrm{C}$ por $15 \mathrm{~s} ; 45^{\circ} \mathrm{C}$ por $30 \mathrm{~s}$; $50^{\circ} \mathrm{C}$ por $15 \mathrm{~s} ; 50^{\circ} \mathrm{C}$ por $30 \mathrm{~s} ; 55^{\circ} \mathrm{C}$ por $15 \mathrm{~s}$; e $55^{\circ} \mathrm{C}$ por $30 \mathrm{~s}$. A faixa de temperatura, o tempo de exposição e os métodos usados foram definidos segundo Oster (2004), que utilizou o tratamento térmico no controle de $B$. dothidea. Após cada tratamento, os tubos foram colocados em água a $1-2^{\circ} \mathrm{C}$ para deter a exposição dos conídios às temperaturas avaliadas. Alíquotas de $0,1 \mathrm{~mL}$ de cada tubo foram transferidas para placas com BDA acidificado (pH 4,5 ajustado com ácido lático a
$85 \%$ ), as quais foram incubadas a $22^{\circ} \mathrm{C}$ por sete dias, sob luz fluorescente contínua (luz do dia).

Para avaliação da sensibilidade de conídios de C. perennans à radiação $\mathrm{UV}-\mathrm{C}$, foram conduzidos dois experimentos. Uma suspensão de $3 \mathrm{~mL}$, com $5 \times 10^{2}$ conídios $\mathrm{mL}^{-1}$ do patógeno em placas de Petri esterilizadas ( $6 \mathrm{~cm}$ de diâmetro), foi submetida às doses de radiação UV-C 0,018, 0,037, 0,075 e $0,150 \mathrm{~kJ} \mathrm{~m}^{-2}$, no primeiro experimento, e $0,375,0,750,1,500 \mathrm{e}$ $3,000 \mathrm{~kJ} \mathrm{~m}^{-2}$, no segundo. Em ambos os experimentos, o tratamento testemunha não recebeu radiação UV-C. As doses de radiação UV-C foram definidas de acordo com os trabalhos de Moy (1983) e Marquenie et al. (2002). Após cada tratamento, alíquotas de $0,1 \mathrm{~mL}$ de cada placa foram transferidas para placas com BDA acidificado ( $\mathrm{pH} 4,5$ ajustado com ácido lático a 85\%) e incubadas a $22^{\circ} \mathrm{C}$ por sete dias, sob luz fluorescente contínua (luz do dia).

Para avaliação dos tratamentos com água aquecida e com radiação UV-C, foi determinada a sobrevivência de conídios nas placas, estimada pelo número de unidades formadoras de colônias (UFC). Foi utilizado o delineamento inteiramente casualizado, com seis repetições para o tratamento de água aquecida e três repetições para radiação UV-C. A unidade experimental foi representada pela placa. Os dados de número de UFC foram transformados para $(\mathrm{x}+1)^{0,5}$ e submetidos à análise de variância (ANOVA) utilizando o programa Sanest (Zonta \& Machado, 1987).Asmédias dos tratamentos foram comparadas pelo teste de Duncan, a 5\% de probabilidade.

Para avaliar a eficiência dos tratamentos com água aquecida e com radiação UV-C na desinfestação de frutos, foram utilizadas maçãs 'Fuji Kiku', armazenadas por oito meses em AC. Os frutos foram selecionados e desinfestados com solução aquosa preparada com hipoclorito de sódio a $2 \%$, água destilada e álcool $\left(92,8^{\circ} \mathrm{GL}\right)$, na proporção de 4,5:4,5:1, durante $3 \mathrm{~min}$. Os frutos foram enxaguados em água destilada e, em seguida, secos com papel toalha. Uma suspensão com $1 \times 10^{6}$ conídios $\mathrm{mL}^{-1}$ de $C$. perennans foi aspergida nas maçãs e, após quatro horas a $20^{\circ} \mathrm{C}$, os frutos foram submetidos aos tratamentos com água aquecida e com radiação UV-C mais eficientes dos experimentos in vitro - aspersão de água aquecida a $20^{\circ} \mathrm{C}$ por $30 \mathrm{~s}$ (testemunha), a $50^{\circ} \mathrm{C}$ por $15 \mathrm{~s}$ e a $50^{\circ} \mathrm{C}$ por $30 \mathrm{~s}$; sem radiação UV-C (testemunha), e doses de radiação UV-C de $0,375,0,750$ e $1,500 \mathrm{~kJ} \mathrm{~m}^{-2}$. Os tratamentos foram implementados na linha de seleção de maçãs, 
equipada com rolos recobertos com escova de náilon com diâmetro total de $38 \mathrm{~cm}$ e rotação constante de $108 \mathrm{rpm}$.

Nos experimentos com radiação UV-C, as irradiâncias espectrais das fontes monocromáticas foram obtidas antes da exposição das amostras, segundo as normas técnicas NBR IEC 60335-2-27 e NBR ISO/IEC 17025 (Associação Brasileira de Normas Técnicas, 2000, 2005). A radiação foi aferida com radiômetro manual UVX calibrado com o espectrorradiômetro IL2000, conforme sugerido por Souza (2005), e a dose foi calculada pelo período de exposição à radiação utilizada.

Em ambos os experimentos, após os tratamentos, as maçãs de cada unidade experimental foram imersas consecutivamente em $300 \mathrm{~mL}$ de água destilada e esterilizada, contendo Tween $80(0,001 \%)$, e submetidas à lavagem por sonicação durante $30 \mathrm{~s}$. Em seguida, amostras de $0,1 \mathrm{~mL}$ de água foram retiradas de cada solução e cultivadas em BDA acidificado $(\mathrm{pH} 4,5$ ajustado com ácido lático a $85 \%$ ), por sete dias a $22^{\circ} \mathrm{C}$, sob luz fluorescente contínua (luz do dia). A contagem de colônias desenvolvidas (UFC) foi utilizada para estimar a sobrevivência dos conídios, e os valores foram expressos em percentagem de controle em relação à testemunha.

Utilizou-se o delineamento inteiramente casualizado, e a unidade experimental foi composta por quatro repetições de dois frutos. Os dados foram transformados para $(\mathrm{x}+1)^{0,5}$ e submetidos à análise de variância (ANOVA) utilizando o programa Sanest (Zonta \&
Machado, 1987), e as médias foram comparadas pelo teste de Duncan, a 5\% de probabilidade.

\section{Resultados e Discussão}

Pelas análises de microscopia eletrônica de varredura, observou-se a colonização das lenticelas em maçãs 'Maxi Gala' submetidas à inoculação de C. perennans, com crescimento profuso de micélio e esporulação do patógeno (Figura 1). Em maçãs 'Fuji Kiku', além da colonização das lenticelas, observou-se a formação de micélio na epiderme.

Em maçãs 'Cox's Orange Pippin', foi observado que a penetração deste patógeno pode ocorrer pelas aberturas naturais, como a calicinal e a peduncular, e também pelas lenticelas, visto que ele desenvolve a podridão quando inoculado nesses pontos (Edney, 1956). Todavia, não foi localizado nenhum trabalho relatando a colonização da epiderme sem ferimento, como foi observado em maçãs 'Fuji Kiku' no presente trabalho. Essa informação é importante, pois a epiderme, que seria a principal barreira contra patógenos, pode representar importante via de infecção de $C$. perennans, mesmo quando não há ferimentos. $\mathrm{O}$ estádio de maturação avançada, de quatro e sete meses em AC, dos frutos 'Maxi Gala' e 'Fuji Kiku', respectivamente, e a temperatura de incubação de $22^{\circ} \mathrm{C}$, utilizados no presente trabalho, provavelmente facilitaram a infecção e a colonização de C. perennans, que são favorecidos pelo aumento do tempo de armazenamento dos frutos e temperaturas próximas de $20^{\circ} \mathrm{C}$ (Edney, 1956). Os conídios de C. perennans podem estar presentes nas lenticelas após

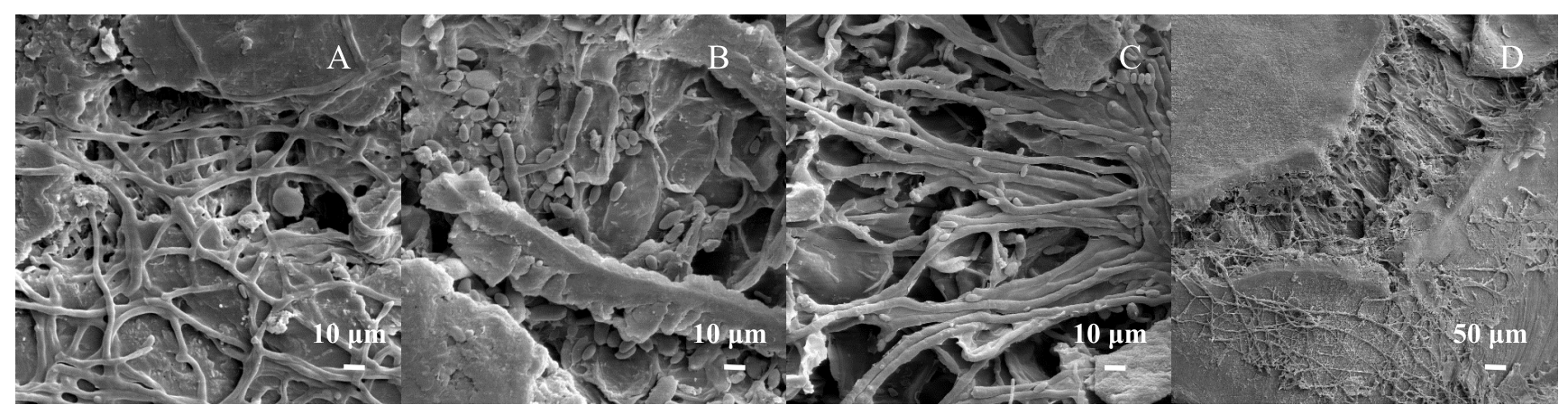

Figura 1. Imagens obtidas por meio de microscopia eletrônica de varredura da colonização da epiderme de maçãs 'Maxi Gala' (A, B e C) e 'Fuji Kiku' (D) após inoculação de Cryptosporiopsis perennans. A, presença de micélio; B e C, presença de micélio e conídios nas lenticelas de maçãs 'Maxi Gala'; D, formação de micélio nas lenticelas e tecido adjacente de maçãs 'Fuji Kiku'. 
a colheita, mesmo em frutos provenientes de pomares protegidos quimicamente durante o ciclo vegetativo, já que essas estruturas restringem o acesso de fungicidas (Edney, 1970). Conforme Dugan et al. (1993), os conídios desse patógeno tendem a aderir às lenticelas e às rachaduras da cutícula, mas os autores não relatam a possibilidade dos conídios serem gerados nas lenticelas, como observado no presente trabalho. Essa constatação justifica o uso de controle cultural e químico no campo, preferencialmente em associação com métodos físicos, químicos e biológicos de controle pós-colheita, visando diminuir a população de $C$. perennans presente na superfície dos frutos.

$\mathrm{Na}$ avaliação da sensibilidade de $C$. perennans à água aquecida, todos os tratamentos diminuíram a sobrevivência dos conídios quando comparados à testemunha (Tabela 1). Para a temperatura de $45^{\circ} \mathrm{C}$, a elevação no tempo de exposição de 15 para $30 \mathrm{~s}$ reduziu a sobrevivência dos conídios. Para as temperaturas de 50 e $55^{\circ} \mathrm{C}$, independentemente do tempo de exposição, a sobrevivência foi ainda mais reduzida, com o controle superior a 99\%. Resultados semelhantes foram obtidos por Marquenie et al. (2002), que observaram maior inativação dos conídios de $B$. cinerea e Monilinia fructigena com o aumento na temperatura e a duração do tratamento. Conforme Oster (2004), a sobrevivência de conídios de $B$. dothidea foi inibida na temperatura de $58^{\circ} \mathrm{C}$ durante $60 \mathrm{~s}$. A maior sensibilidade de conídios de $C$. perennans ao calor, em comparação a $B$. dothidea, pode estar relacionada às diferenças nas características genéticas entre esses dois patógenos ou ao maior tamanho dos conídios de $B$. dothidea (5-8x15-29 $\mu \mathrm{m})$ em relação aos de C. perennans (1-2x5-8 $\mu \mathrm{m})$ (Bogo et al., 2008). Fato semelhante foi observado por Marquenie et al. (2002), que concluíram que os conídios de $M$. fructigena foram mais sensíveis ao calor do que os de $B$. cinerea.

A eficácia do tratamento térmico na redução da viabilidade do patógeno pode ainda ser medida pela redução no crescimento micelial (Ferguson et al., 2000). Diferenças de sensibilidade do micélio dos patógenos ao tratamento hidrotérmico foram relatadas por Karabulut et al. (2002). Segundo esses autores, o crescimento micelial de $M$. fructicola foi inibido pela exposição a $50^{\circ} \mathrm{C}$ durante $10 \mathrm{~s}$, enquanto o crescimento de $P$. expansum só foi inibido a $60^{\circ} \mathrm{C}$ durante $20 \mathrm{~s}$. Barkai-Golan \& Phillips (1991) observaram ainda que a resposta do patógeno ao calor pode ser influenciada pelo conteúdo de umidade dos esporos, pela atividade metabólica do patógeno, pela idade do inóculo e pela composição química da água do tratamento.

A radiação UV-C reduziu a sobrevivência dos conídios de $C$. perennans in vitro, em todas as doses avaliadas (Tabela 1). No primeiro experimento, as doses de 0,037 a $0,150 \mathrm{~kJ} \mathrm{~m}^{-2}$ diminuíram em mais de $70 \%$ a sobrevivência dos conídios do patógeno em relação à testemunha. No segundo experimento, as doses de $0,750,1,500$ e $3,000 \mathrm{~kJ} \mathrm{~m}^{-2}$ reduziram em mais de $99 \%$ a sobrevivência dos conídios em relação à testemunha. Neste experimento, a exposição à dose de $0,375 \mathrm{~kJ} \mathrm{~m}^{-2}$ foi menos eficiente em relação às doses maiores, mas ainda assim apresentou controle de $86,4 \%$.

Marquenie et al. (2002) observaram aumento na eficiência da radiação UV-C no controle de conídios de $B$. cinerea e $M$. fructigena com o incremento na dose utilizada de 0,1 a $15 \mathrm{~kJ} \mathrm{~m}^{-2}$. Moy (1983) verificou que

Tabela 1. Número de unidades formadoras de colônias (UFC) obtido de suspensões de Cryptosporiopsis perennans submetidas a tratamentos com água aquecida e doses de radiação UV-C.

\begin{tabular}{|c|c|c|}
\hline Tratamento & Número de UFC ${ }^{(1)}$ & Controle $(\%)^{(2)}$ \\
\hline & \multicolumn{2}{|c|}{ Água aquecida } \\
\hline $28^{\circ} \mathrm{C}$ por $15 \mathrm{~s}$ (testemunha) & $74,2 \mathrm{a}$ & - \\
\hline $45^{\circ} \mathrm{C}$ por $15 \mathrm{~s}$ & $31,3 b$ & 57,8 \\
\hline $45^{\circ} \mathrm{C}$ por $30 \mathrm{~s}$ & $13,5 \mathrm{c}$ & 81,8 \\
\hline $50^{\circ} \mathrm{C}$ por $15 \mathrm{~s}$ & $0,5 \mathrm{~d}$ & 99,4 \\
\hline $50^{\circ} \mathrm{C}$ por $30 \mathrm{~s}$ & $0,0 \mathrm{~d}$ & 100,0 \\
\hline $55^{\circ} \mathrm{C}$ por $15 \mathrm{~s}$ & $0,1 \mathrm{~d}$ & 99,9 \\
\hline $55^{\circ} \mathrm{C}$ por $30 \mathrm{~s}$ & $0,0 \mathrm{~d}$ & 100,0 \\
\hline \multirow[t]{2}{*}{ CV (\%) } & 19,6 & - \\
\hline & \multicolumn{2}{|c|}{ Radiação UV-C $\left(\mathrm{kj} \mathrm{m}^{-2}\right)$ experimento 1} \\
\hline Sem radiação & $154,1 \mathrm{a}$ & - \\
\hline 0,018 & $82,5 \mathrm{~b}$ & 46,5 \\
\hline 0,037 & $36,5 \mathrm{c}$ & 76,3 \\
\hline 0,075 & $9,6 \mathrm{~d}$ & 93,8 \\
\hline$\underline{0,150}$ & $3,0 \mathrm{e}$ & 98,1 \\
\hline \multirow{2}{*}{$\mathrm{CV}(\%)$} & 3,6 & \\
\hline & \multicolumn{2}{|c|}{ Radiação UV-C $\left(\mathrm{kj} \mathrm{m}^{-2}\right)$ experimento 2} \\
\hline Sem radiação & $44,9 \mathrm{a}$ & - \\
\hline 0,375 & $6,1 \mathrm{~b}$ & 86,4 \\
\hline 0,750 & $0,3 \mathrm{c}$ & 99,3 \\
\hline 1,500 & $0,0 \mathrm{c}$ & 100,0 \\
\hline$\underline{3,000}$ & $0,0 \mathrm{c}$ & 100,0 \\
\hline $\mathrm{CV}(\%)$ & 12,9 & - \\
\hline
\end{tabular}

${ }^{(1)}$ Médias ( $m=3$ e 6 para os tratamentos com água aquecida e com doses de radiação UV-C, respectivamente) seguidas de letras iguais não diferem entre si pelo teste de Duncan, a $5 \%$ de probabilidade. (2) Controle $(\%)=100[$ (número colônias por placa na testemunha número colônias por placa do tratamento)/número colônias por placa na testemunha)]. 
a radiação UV-C na dose de $1,1 \mathrm{~kJ} \mathrm{~m}^{-2}$ é suficiente para reduzir a viabilidade de $R$. stolonifer in vitro. Segundo Camili et al. (2004), a dose de $0,84 \mathrm{~kJ} \mathrm{~m}^{-2}$ apresenta efeito germicida sobre conídios de $B$. cinerea, e as doses de 0,2 a $0,6 \mathrm{~kJ} \mathrm{~m}^{-2}$ retardam e diminuem a germinação dessas estruturas. Portanto, as doses de radiação UV-C eficientes para controle dos esporos de $R$. stolonifer, B. cinerea e C. perennans são similares, o que demonstra o potencial de sua implementação comercial para o controle em pós-colheita dos diferentes patógenos que ocorrem em maçãs.

A sobrevivência de conídios de C. perennans na epiderme das maçãs submetidas à inoculação do patógeno e à aspersão de água aquecida a $50^{\circ} \mathrm{C}$ por 15 e 30 s foi reduzida em 97,7 e $99,2 \%$, respectivamente, em relação à testemunha (Tabela 2). Esse resultado corrobora os resultados de outros autores, que utilizaram tratamentos com aspersão de água com temperaturas altas e menores períodos de exposição para o controle de podridões (Fallik et al., 2001; Karabulut et al., 2002). Maçãs 'Golden Delicious' com infecção natural ou submetidas à inoculação de $P$. expansum e tratadas com aspersão de água a $55^{\circ} \mathrm{C}$ por $15 \mathrm{~s}$ apresentaram menor incidência da doença, sem que isso tenha comprometido a qualidade físico-química dos frutos (Fallik et al., 2001). Resultados semelhantes foram obtidos por Oster (2004), que não detectou alteração na qualidade de maçãs 'Fuji' submetidas à aspersão de água a $58^{\circ} \mathrm{C}$ durante $60 \mathrm{~s}$, para controle de $B$. dothidea.

Tabela 2. Número de unidades formadoras de colônias (UFC) de conídios obtidos de maçãs 'Fuji Kiku' submetidas à inoculação de Cryptosporiopsis perennans e a tratamentos de aspersão de água aquecida e doses de radiação UV-C.

\begin{tabular}{lcc}
\hline Tratamento & UFC $^{(1)}$ & Controle $(\%)^{(2)}$ \\
\hline & Aspersão de água aquecida \\
$20^{\circ} \mathrm{C}$ por 30 s (testemunha) & $102,2 \mathrm{a}$ & - \\
$50^{\circ} \mathrm{C}$ por $15 \mathrm{~s}$ & $2,1 \mathrm{~b}$ & 97,7 \\
$50^{\circ} \mathrm{C}$ por 30 s & $1,0 \mathrm{~b}$ & 99,2 \\
\hline $\mathrm{CV}(\%)$ & 31,8 \\
\hline \\
Sem radiação & Radiação UV-C $\left(\mathrm{kj} \mathrm{m}^{-2}\right)$ \\
0,375 & $60,9 \mathrm{a}$ & - \\
0,750 & $3,6 \mathrm{~b}$ & 94,0 \\
1,500 & $0,9 \mathrm{~b}$ & 98,6 \\
$\mathrm{CV}(\%)$ & $2,2 \mathrm{~b}$ & 96,3 \\
\hline
\end{tabular}

(1)Médias ( $\mathrm{n}=4$, com dois frutos cada uma) seguidas de letras iguais não diferem entre si pelo teste de Duncan, a $5 \%$ de probabilidade. ${ }^{(2)}$ Controle $(\%)=100\left[\left(n^{\circ}\right.\right.$ colônias por placa na testemunha $-n^{\underline{0}}$ colônias por placa do tratamento) $/ \mathrm{n}^{\mathrm{o}}$ colônias por placa na testemunha)].
A imersão de frutos em água aquecida tem mostrado eficiência no controle de doenças em maçãs (Maxin et al., 2005). Todavia, o alto custo para o aquecimento de grandes volumes de água torna o tratamento por imersão inviável em escala comercial (Rodov et al., 1995). Além disso, a exposição dos frutos a tratamentos de imersão em água aquecida por mais de $20 \mathrm{~s}$, citados como eficientes, interfere no rendimento de processamento de empacotadoras de maçãs do Sul do Brasil. A aspersão de água aquecida associada à escovação dos frutos por períodos curtos (até $20 \mathrm{~s}$ ) apresenta maiores vantagens no controle de doenças em relação ao tratamento térmico por imersão (Fallik et al., 2001; Karabulut et al., 2002). A aspersão dos frutos com água aquecida associada à escovação pode remover conídios e diminuir a sua viabilidade (Couey, 1989). A aspersão por períodos curtos permite o uso de temperaturas maiores, que são letais para a maioria dos patógenos, sem aumentar substancialmente a temperatura interna dos frutos e, portanto, sem acelerar o seu amadurecimento ou causar algum dano à epiderme.

As doses de radiação UV-C 0,375, 0,750 e $1,500 \mathrm{~kJ} \mathrm{~m}^{-2}$ foram igualmente eficientes no controle dos conídios de C.perennans presentes na epiderme das maçãs (controle de 94 a 98\%) (Tabela 2). Em condições de manejo comercial de maçãs 'Fuji', o tratamento com radiação UV-C na dose de $5,9 \mathrm{~kJ} \mathrm{~m}^{-2}$ proporcionou entre 90 e $100 \%$ de controle da contaminação superficial de P. expansum (Valdebenito-Sanhueza \& Maia, 2001). No presente trabalho, foram utilizadas doses inferiores a essas, as quais foram eficientes no controle dos conídios de C. perennans em maçãs 'Fuji Kiku'. O uso de doses de radiação UV-C menores para controle dos patógenos causadores de podridões de maçãs é importante, uma vez que o processo de classificação e embalagem é rápido e, portanto, requer tratamentos eficientes com períodos curtos de exposição. Outra vantagem do uso de radiação UV-C, não avaliada no presente trabalho, é a indução de resistência dos tecidos vegetais aos patógenos, conforme observado em batata, cebola, tangerina e maçã (Brown et al., 2001; Stevens et al., 2004, 2005; Yaun, 2004). Stevens et al. (2005) usaram a dose de radiação UV-C de $7,5 \mathrm{~kJ} \mathrm{~m}^{-2}$ para a indução de resistência e redução de podridões em maçãs 'Golden Delicious', inoculadas com Colletotrichum gloeosporioides. 
No presente trabalho, observou-se que as doses de radiação UV-C eficientes nos experimentos in vitro e in vivo foram semelhantes. Porém, Mercier et al. (2001) relataram que, apesar de ser altamente germicida a conídios de $B$. cinerea, a radiação UV-C $(0,22$ a $2,20 \mathrm{~kJ} \mathrm{~m}^{-2}$ ) não controla a infecção em pimentões inoculados 24 horas antes do tratamento. Nesse caso, os conídios provavelmente germinaram e infectaram os frutos durante 24 horas e, portanto, não foram atingidos pela radiação UV-C.

O emprego de tratamentos físicos para o controle de propágulos de patógenos presentes na superfície das maçãs é de grande importância, já que eles são os principais responsáveis pelo desenvolvimento de podridões durante a armazenagem, transporte e comercialização, especialmente em frutos destinados à exportação. $\mathrm{O}$ desenvolvimento de equipamentos para instalação nas empacotadoras será necessário para viabilizar o uso comercial dessas técnicas.

\section{Conclusões}

1. O fungo Cryptosporiopsis perennans, ao colonizar a epiderme das maçãs, produz abundante micélio e conídios nas lenticelas e nas áreas adjacentes.

2. A aplicação de água aquecida a $50^{\circ} \mathrm{C}$ durante $15 \mathrm{~s} \mathrm{e}$ dose de radiação UV-C de $0,75 \mathrm{~kJ} \mathrm{~m}^{-2}$ reduzem em mais de $99 \%$ a sobrevivência de conídios de C. perennans in vitro.

3. A desinfestação de C. perennans em maçãs 'Fuji Kiku' é obtida com aspersão de água aquecida a $50^{\circ} \mathrm{C}$ por $15 \mathrm{~s}$ e radiação UV-C na dose de $0,375 \mathrm{~kJ} \mathrm{~m}^{-2}$.

\section{Agradecimentos}

Ao Conselho Nacional de Desenvolvimento Científico e Tecnológico, à Coordenação de Aperfeiçoamento de Pessoal de Nível Superior e ao Projeto Inova Maçã, pelo apoio financeiro.

\section{Referências}

ASSOCIAÇÃO BRASILEIRA DE NORMAS TÉCNICAS. NBR IEC 60335-2-27: requisitos particulares para aparelhos de exposição da pele a radiação ultravioleta e infravermelho. Rio de Janeiro: ABNT, 2000. 12p.

ASSOCIAÇÃO BRASILEIRA DE NORMAS TÉCNICAS. NBR ISO/IEC 17025: requisitos gerais para competência de laboratórios de ensaio e calibração. Rio de Janeiro: ABNT, 2005. 31p.
BARKAI-GOLAN, R.; PHILLIPS, D.J. Postharvest heat treatment of fresh fruits and vegetables for decay control. Plant Disease, v.75, p.1085-1089, 1991.

BOGO,A.; MAFFIOLETTI,M.A.;VALDEBENITO-SANHUEZA, R.M.; CASA, R.T. Caracterização morfológica de isolados de Cryptosporiopsis perennans em diferentes meios de cultura. Tropical Plant Pathology, v.33, p.248-251, 2008.

BROWN, J.E.; LU, T.Y.; STEVENS, C.; KHAN, V.A.; LU, J.Y.; WILSON, C.L.; COLLINS, D.J.; WILSON, M.A.; IGWEGBE, E.C.K.; CHALUTZ, E.; DROBY, S. The effect of low dose ultraviolet light-C seed treatment on induced resistance in cabbage to black rot (Xanthomonas campestris pv. campestris). Crop Protection, v.20, p.873-883, 2001.

CAMILI, E.C.; BENATO, E.A.; PASCHOLATI, S.F.; CIA, P. Avaliação de irradiação UV-C aplicada em pós-colheita na proteção de uva 'Itália' contra Botrytis cinerea. Summa Phytopathologica, v.30, p.306-313, 2004

CASTRO, L.A.S. de. Processamento de amostras para microscopia eletrônica de varredura. Pelotas: Embrapa Clima Temperado, 2002. 37p. (Embrapa Clima Temperado. Documentos, 93).

CIVELlO, P.M.; MARTÍNEZ, G.A.; CHAVES, A.R.; AÑÓN, M.C. Heat treatments delay ripening and postharvest decay of strawberry fruit. Journal of Agricultural and Food Chemistry, v.45, p.4589-4594, 1997.

COUEY, H.M. Heat treatment for control of postharvest diseases and insect pests of fruits. HortScience, v.24, p.198-202, 1989.

DUGAN, F.M.; GROVE, G.G.; ROGERS, J.D. Comparative studies of Cryptosporiopsis curvispora and C. perennans. I. Morphology and Pathogenic Behavior. Mycologia, v.85, p.551-564, 1993.

EDNEY, K.L. Some experiments with thiabendazole and benomyl as post-harvest treatments for the control of storage rots of apples. Plant Pathology, v.19, p.189-193, 1970.

EDNEY, K.L. The rotting of apples by Gloeosporium perennans Zeller \& Childs. Annals of Applied Biology, v.44, p.113-128, 1956.

FALLIK, E.; TUVIA-ALKALAI, S.; FENG, X.; LURIE, S. Ripening characterisation and decay development of stored apples after a short pre-storage hot water rinsing and brushing. Innovative Food Sciences \& Emerging Technologies, v.2, p.127-132, 2001.

FERGUSON, I.B.; BEN-YEHOSHUA, S.; MITCHAM, E.J.; MCDONALD, R.E. Postharvest heat treatments: introduction and workshop summary. Postharvest Biology and Technology, v.21, p.1-6, 2000 .

GORDON, G.; PACEY, G.E.; BUBNIS, B.P. Analytical methods for disinfectants and disinfection by-products. In: CRAUN, G.F. (Ed.). Safety of water desinfestion: balancing chemical and microbial risks. Washington: ILSI Press, 1993. p.221-237.

GUERRA, D.S. Predisposição de macieiras (Malus domestica Borkh)cominfecçõesviraisa Cryptosporiopsisperennans(Zeller\& Childs) Wollenweber em frutos e Colletotrichum gloeosporioides (Penzig.) Penzig. \& Sacc. em folhas. 2007. 99p. Tese (Doutorado) - Universidade Federal do Rio Grande do Sul, Porto Alegre.

KARABULUT, O.A.; COHEN, L.; WIESS, B. Control of brown rot and blue mold of peach and nectarine by short hot water brushing 
and yeast antagonists. Postharvest Biology and Technology, v.24, p.103-111, 2002.

LURIE, S.; FALLIK, E.; KLEIN, J.D. Postharvest heat treatment of apples to control San Jose scale (Quadraspidiotus perniciosus Comstock) and blue mold (Penicillium expansum Link) and maintain fruit firmness. Journal of the American Society for Horticultural Science, v.123, p.110-114, 1998.

MARQUENIE, D.; LAMMERTYN, J.; GEERAERD, A.H.; SOONTJENS, C.; VAN IMPE, J.F.; NICOLAI, B.M.; MICHIELS, C.W. Inactivation of conidia of Botrytis cinerea and Monilinia fructigena using UV-C and heat treatment. International Journal of Food Microbiology, v.74, p.27-35, 2002.

MAXIN, P.; HUYSKENS-KEIL, S.; KLOPP, K.; EBERT, G. Control of postharvest decay in organic grown apples by hot water treatment. Acta Horticulturae, n.682, p.2153-2158, 2005.

MERCIER, J.; BAKA, M.; REDDY, B.; CORCUFF, R.; ARUL, J. Short-wave ultraviolet irradiation for control of decay caused by Botrytis cinerea in Bell pepper: induced resistance and germicidal effects. Journal of the American Society for Horticultural Science, v.126, p.128-133, 2001.

MOY, J.H. Radurization and radicidation: fruits and vegetables. In: JOSEPHSON, E.S.; PETERSON, M.S. (Ed.). Preservation of food by ionizing radiation. Boca Raton: CRC Press, 1983. p.83-108.

OSTER, A.H. Tratamento com calor no controle de Botryosphaeria dothidea (Moug.) Ces. \& De Not.) em maçãs cv. Fuji. 2004. 85p. Tese (Doutorado) - Universidade Federal do Rio Grande do Sul, Porto Alegre.

RODOV, V.; BEN-YEHOSHUA, S.; ALBAGLI, R.; FANG, D.Q. Reducing chilling injury and decay of stored citrus fruit by hot water dips. Postharvest Biology and Technology, v.5, p.119-127, 1995.
SOUZA, J.A.V. Modelo experimental para um novo padrão de espectro de ação. 2005. 77p. Dissertação (Mestrado) - Pontifícia Universidade Católica do Rio Grande do Sul, Porto Alegre.

STEVENS, C.; KHAN, V.A.; WILSON, C.L.; LUA, J.Y.; CHALUTZC, E.; DROBYC, S. The effect of fruit orientation of postharvest commodities following low dose ultraviolet light-C treatment on host induced resistance to decay. Crop Protection, v.24, p.756-759, 2005.

STEVENS, C.; LIU, J.; KHAN, V.A.; LU, J.Y.; KABWE, M.K.; WILSON, C.L.; IGWEGBE, E.C.K.; CHALUTZ, E.; DROBY, S. The effects of low-dose ultraviolet light-C treatment on polygalacturonase activity, delay ripening and Rhizopus soft rot development of tomatoes. Crop Protection, v.23, p.551-554, 2004.

VALDEBENITO-SANHUEZA, R.M. Ocorrência de Cryptosporiopsis perennans em macieiras 'Fuji' no Sul do Brasil. Summa Phytopathologica, v.28, p.204-206, 2002.

VALDEBENITO-SANHUEZA, R.M.; MAIA, L. Utilização da luz ultravioleta (UV-C) na proteção de maçãs 'Fuji' da podridão por Penicillium expansum. Bento Gonçalves: Embrapa Uva e Vinho, 2001. 20p. (Embrapa Uva e Vinho. Boletim de pesquisa e desenvolvimento, 10).

WOLFE, R.L. Ultraviolet disinfection of potable water. Environmental Science \& Technology, v.24, p.768-772, 1990.

YAUN, B.R.; SUMNER, S.; EIFERT, J.D.; MARCY, J.E. Inhibition of pathogens on fresh produce by ultraviolet energy. International Journal of Food Microbiology, v.90, p.1-8, 2004.

ZONTA, E.P.; MACHADO, A.A. SANEST - Sistema de análise estatística para microcomputadores. Pelotas: DMEC / IFM / UFPel, 138p. 1987.

Recebido em 28 de abril de 2009 e aprovado em 15 de janeiro de 2010

Pesq. agropec. bras., Brasília, v.45, n.2, p.124-131, fev. 2010 